\title{
Radiology Needs Robust Dialogue
}

\author{
Joseph C. Thomas, BS, Richard B. Gunderman, MD, PhD \\ Department of Radiology, Indiana University School of Medicine, Indianapolis, Indiana
}

For it is not possible for anyone to experience a greater evil than hating arguments.

-Socrates, in Plato's Phaedo [1]

To promote its own intellectual and cultural vitality, the field of radiology needs to promote increasingly robust dialogue, and radiologists need to further enhance their appetite for reasoned argument, debate, assertions and counterassertions, and the art of refutation. Assertions that go untested by argument, whether they be true or false, can never be so thoroughly understood as those that have been tested. And those that are inadequate or not as well stated as they should be may languish unattended and unimproved. Bad ideas are culled and good ideas are strengthened by challenge.

This principle shines forth in many great works of Western civilization. For example, Plato (428-348 bc) wrote not treatises but dialogues [2]. His goal was not to tell his readers what to think, but to draw them into a conversation between two people who saw matters differently. He believed that the truth was not the sort of thing that someone could tell us but instead had to be discovered by each of us for ourselves. By joining in the conversation, which Plato regarded as one of the defining features of humanity, we would not only understand matters better but also bring ourselves to life.

Thomas Aquinas (1225-1274) employed a similar technique. His Summa Theologica embodies a dialogical approach to learning [3]. After posing a question, he states the antithesis and arguments on its behalf, followed by the thesis and its supporting arguments, and then he provides counterarguments to

This is the author's manuscript of the article published in final edited form as:

Thomas, J. C., \& Gunderman, R. B. (2018). Radiology Needs Robust Dialogue. Journal of the American College of Radiology. https://doi.org/10.1016/j.jacr.2018.07.029 
each of the antithetical arguments. This approach ensures that readers see both sides - or even multiple sides - of every argument. Aquinas was teaching students not merely what to think but how to think well.

A final example of the dialogic approach in the Western tradition is the adversarial system in the common law [4]. Two adversaries are identified, such as one for the prosecution and one for the defense, and each presents his or her party's case or position and attempts to refute the other side. Evidence is put to the test and witnesses are cross-examined. Sitting before the adversaries is an impartial jury or judge. The underlying rationale is this: justice is most likely to be served when arguments from both sides of an issue have a thorough and fair hearing.

The pursuit of understanding is best likened to a quest or perhaps a struggle. When an investigator publishes a study's results, the adequacy of the publication's argument, the quality of its evidence, and the degree to which alternative explanations and counterarguments have been considered should all factor into a final appraisal. If the argument of the publication is important, it should meet with challenges from other investigators, who question its conclusions, its methods, and the quality of evidence it provides. Such challenges are not personal affronts but signs of a culture of robust professional discourse.

As anyone who has ever attempted to draft a committee statement on a controversial issue knows, efforts to avoid offending anyone typically end up pleasing no one. The result is often a tasteless goulash. When such statements are shared with the membership of an organization, they threaten to sap engagement with the topic and put everyone to sleep. A far better strategy is to stage a reasoned dialogue or even debate on the topic, allowing everyone present to hear the different sides of the issue presented as clearly and effectively as possible.

Over the years, we have attended many meetings at which a fear of dialogue has squelched thorough examination of a question and helped pave the way for a seemingly unanimous decision that proved to be not only wrong but very costly. Those presiding sometimes mistakenly regard an absence of lively debate 
as a sign of their own leadership effectiveness. In other cases, steps have been taken to avoid open debate, for fear that it would show a lack of unity or resolve, and those present have been cautioned that, once a decision is reached, no hint of disagreement can be tolerated.

On this account, a successful meeting is one at which only a single point of view is advanced, or alternative points of view are summarily dispensed with, and the meeting ends early, because no one has anything provocative to say. The goal above all others is to reach a decision, whether that decision is a well-considered one or not. And once the decision is reached, it is to be treated as definitive and accepted by everyone in the room. In the ideal, all decisions would be unanimous, but where that is not possible, they should go forward with the appearance of much the same thing, universal assent.

Our first loyalty, however, should be not to what is nonthreatening or politically expedient, but to what is true, well reasoned, and well supported. We cannot determine the degree to which a proposed course of action is appropriate until we have thoroughly explored it from multiple different points of view. This perspective was embodied in the approach of Alfred P. Sloan (1875-1966), the most important chief executive in the history of General Motors, at board meetings. If a proposition met with no opposition, Sloan would table it until later when someone could present strong counterarguments [5].

The so-called "devil's advocate," a once-official position within the Catholic Church, has a similar origin [6]. As arguments are advanced in support of a candidate for canonization (sainthood), the mission of the devil's advocate is to probe weaknesses and inconsistencies in the evidence presented and to seek to reveal any previously unstated character flaws. In any effective dialogue, skepticism has an important role to play, and the devil's advocate position represents an effort to formally validate the role of doubting or interrogating what others are inclined to accept without question.

The dialogic approach favors free speech over the distinction between permissible and impermissible speech. In a field such as radiology, this means both that truth is more likely to win out and that the intellectual faculties of radiologic professionals are more likely to be strengthened when no ideas are 
ruled out of court and every idea is open to lively debate and opposition. Ideas are unacceptable not because they are politically incorrect, but because they have not received a thorough vetting. As the old saying goes, the best disinfectant is sunlight.

Consider the defense of free speech offered almost 90 years ago by University of Chicago President Robert Hutchins (1899-1977), when the Communist Party's candidate for president was invited by a student group to lecture on campus. Wrote Hutchins,

Our students should have freedom to discuss any problem that presents itself. The cure for ideas we oppose lies in open discussion, not inhibition. Free inquiry is indispensable to the good life, universities exist for such inquiry, and without it they cease to be universities [7].

What Hutchins says of universities may be said — needs to be said — with equal vigor regarding professions, such as medicine, and disciplines within medicine, such as radiology. Radiology exists thanks to remarkable techniques for shining a light on inner recesses of the human body that had previously languished in darkness. We bring to light what would otherwise be invisible. It is especially fitting, then, that radiology should embrace the principles of free speech and encourage open and lively dialogue regarding the most important questions before it.

In practice, the promotion of robust dialogue might take many forms. In educational programs, learners might not only hear but take an active part in debates over important issues of the day. Professional meetings and journals might format some of their content in a way that promotes a disputational approach. Policymaking bodies within radiology should operate as transparently as possible, encouraging members of the profession to take an active role in ensuring that new initiatives receive a thorough vetting from multiple points of view.

Practical examples abound $[8,9,10]$. The Emergency Medicine program at University of Pennsylvania utilized debates to educate residents regarding patient safety concepts, process improvement, and identifying medical errors. The New York University Medical Center's Department of Obstetrics and 
Gynecology found substantially higher tests scores for resident groups who participated in debates instead of presentations. It may be a more effective educational format than standard journal clubs. Debate also encourages personal growth in oral communication skills, critical thinking, and empathy [11].

Yet there are challenges. All parties need to buy in. Selection of topics requires real effort. And preparation demands active thinking, as opposed to mere summarization. A potential pitfall is dualism, the view that any contested topic can be represented by only two opposing views. So long as participants are aware of this liability, however, they can take care to ensure that audience members see a full spectrum of views on the matter. Doing so is a crucial part of developing a robust culture of dialogue in which all perspectives receive a fair hearing.

A profession without civil discourse in which everyone speaks in unison is not healthy. At any particular moment in time, everything it is doing may happen to be entirely appropriate, but over time it will wander ever farther from the course that robust dialogue would help it chart. It is important to do the appropriate thing, but it is also important to know why it is appropriate, including the arguments that can be advanced for alternative courses of action. Ultimately, except by chance, no profession's fortunes can exceed the quality of its internal dialogues. 


\section{References}

1. Plato. Phaedo. Available at: http://classics. mit.edu/Plato/phaedo.html.

2. Plato. Collected dialogues. Available at: http://www.sacred-texts.com/cla/plato/index.htm.

3. Aquinas T. The summa theologica. Available at: https://dhspriory.org/thomas/summa/.

4. Plucknett TFT. A concise history of the common law. Available at:

http://oll.libertyfund.org/titles/plucknett-a-concise-history-of-the-common-law.

5. Economist.com. Alfred Sloan, guru. Available at: https://www.economist.com/node/13047099.

6. New Advent. Advocatus diaboli. Available at:

http://www.newadvent.org/cathen/01168b.htm.AccessedJuly1,2018.

7. Hutchins RM. Statement of principles of free expression. Available at:

https://freeexpression.uchicago.edu/page/statement-principles-free-expression. Accessed July 1, 2018.

8. Koklanaris N, MacKenzie A, Fino M, Arslan A, Seubert D. Debate preparation/participation: an active, effective learning tool. Teach Learn Med 2008;20:235-8.

9. Mamtani M, Scott K, DeRoos F, Conlon L. Assessing EM patient safety and quality improvement milestones using a novel debate format. West J Emerg Med 2015;16:943-6.

10. Ong C, Narasimhan K. A novel learning experience: case-based, evidence-based debate. Med Educ 2010;44:515-6.

11. Kennedy R. In-class debates: fertile ground for active learning and the cultivation of critical thinking and oral communication skills. International Journal of Teaching \& Learning in Higher Education 2007;19:183-90. 